\title{
Healthy aging - insights from Drosophila
}

\author{
Konstantin G. Iliadi ${ }^{1}{ }^{*}$, David Knight ${ }^{1}$ and Gabrielle L. Boulianne ${ }^{1,2 *}$ \\ 1 Program in Developmental and Stem Cell Biology, The Hospital for Sick Children, Toronto, ON, Canada \\ 2 Department of Molecular Genetics, University of Toronto, Toronto, ON, Canada
}

\author{
Edited by: \\ Vladimir Titorenko, Concordia \\ University, Canada \\ Reviewed by: \\ Mildred Audrey Pointer, North \\ Carolina Central University, USA \\ William Donald Phillips, The University \\ of Sydney, Australia \\ *Correspondence: \\ Konstantin G. Iliadi and \\ Gabrielle L. Boulianne, Program in \\ Developmental and Stem Cell \\ Biology, The Hospital for Sick \\ Children, TMDT, 101 College Street, \\ Room 12-305, Toronto, ON, Canada \\ M5G $1 L 7$. \\ e-mail: iliadi@sickkids.com \\ gboul@sickkids.ca
}

\begin{abstract}
Human life expectancy has nearly doubled in the past century due, in part, to social and economic development, and a wide range of new medical technologies and treatments. As the number of elderly increase it becomes of vital importance to understand what factors contribute to healthy aging. Human longevity is a complex process that is affected by both environmental and genetic factors and interactions between them. Unfortunately, it is currently difficult to identify the role of genetic components in human longevity. In contrast, model organisms such as $C$. elegans, Drosophila, and rodents have facilitated the search for specific genes that affect lifespan. Experimental evidence obtained from studies in model organisms suggests that mutations in a single gene may increase longevity and delay the onset of age-related symptoms including motor impairments, sexual and reproductive and immune dysfunction, cardiovascular disease, and cognitive decline. Furthermore, the high degree of conservation between diverse species in the genes and pathways that regulate longevity suggests that work in model organisms can both expand our theoretical knowledge of aging and perhaps provide new therapeutic targets for the treatment of age-related disorders.
\end{abstract}

\section{Keywords: Drosophila, lifespan, aging, genetics, environment}

\section{INTRODUCTION}

Aging generally refers to the process of getting chronologically older and it is typically accompanied by senescence, the gradual loss of physiological functions. Both of these processes are to some degree, inevitable for all living organisms. Chronological aging is primarily predetermined by heredity, whereas senescence results from a complex interaction between environmental and genetic factors.

During the last century, advances in medical technology have significantly contributed to extension of human longevity. According to data from the United Nations, US Census Bureau, Statistical Office of the European Communities, and National Institute of Aging (NIA) there are several trends in global aging: (1) The overall population is aging. For the first time in history, people aged 65 and over will outnumber children under the age of 5. (2) Life expectancy is increasing. Most countries, including developing countries, show a steady increase in longevity over time. (3) The number of oldest old is rising. People aged 85 and over are now the fastest growing portion of many national populations. (4) New economic challenges are emerging. Population aging will have dramatic effects on social entitlement programs, labor supply, trade, and savings around the globe and may demand new fiscal approaches to accommodate a changing world (Doriansky et al., 2007). Altogether, these findings further emphasize the need to understand how to promote healthy aging rather than just extending lifespan.

Non-genetic factors such as nutrition, environmental quality, psychosocial factors, and lifestyle play an important role in healthy aging. However, experimental studies have indicated that the heritable component has a significant impact on the senescence of invertebrates and mammals and accounts for approximately 35\% of the variance in lifespan (see Finch and Tanzi, 1997; Finch and Ruvkun, 2001 for details). Over the past few decades and especially since the completion of the Human Genome Project, a great number of studies have been carried out aimed at identifying the genetic factors that affect human lifespan. Despite the wide range of approaches utilized to identify longevity genes in humans including, linkage analysis (Puca et al., 2001; Tan et al., 2004), candidate-gene association analysis (Park et al., 2009; Lopez et al., 2012), and longitudinal studies (Nybo et al., 2003; Soerensen et al., 2010), progress has been limited due to the fact that these methods can be experimentally intensive, time-consuming, and poorly replicated. In addition, it is very difficult to control for variations in environmental conditions. In contrast, it is easier to minimize the effect of environmental conditions, lifestyle, and genetic background in model organisms. Moreover, while studies of longevity in humans are limited to demographic observations of externally apparent symptoms, model organisms can be genetically manipulated and phenotypically characterized in much greater depth allowing theories of aging and age-related disease to be experimentally tested.

Model organisms have also revealed that diverse organisms may share common biological mechanisms regulating longevity (Guarente and Kenyon, 2000; Helfand and Rogina, 2003; Hekimi, 2006). For example, studies have shown that dietary restriction, without malnutrition, can extend lifespan, and delay the onset of age-related pathologies in a wide range of species including yeast, worms, flies, and mammals (Good and Tatar, 2001; Barger et al., 2003; Koubova and Guarente, 2003; Johnson, 2008; Mair and Dillin, 2008; Skinner and Lin, 2010). Similarly, several metabolic processes and signaling pathways have also been shown 
to have an evolutionarily conserved role in aging. For example, the insulin/insulin growth factor (IGF) signaling pathway (Kenyon et al., 1993; Clancy et al., 2001; Tatar et al., 2001; Bluher et al., 2003), histone deacetylases such as rpd3/Sir2 (Kim et al., 1999; Tissenbaum and Guarente, 2001; Rogina et al., 2002), and genes involved in oxidative stress (Phillips et al., 1989; Sohal and Weindruch, 1996; Parkes et al., 1998; Honda and Honda, 1999; Migliaccio et al., 1999; Sun and Tower, 1999; Taub et al., 1999; Tower, 2000), all exert evolutionarily conserved effects on aging and lifespan in a wide range of model organisms. The extent of evolutionary conservation in both the outward signs of aging and the environmental and genetic factors that influence it, suggests that aging itself is an evolutionarily conserved process and not simply an inevitable deterioration of biological systems. As such, studies of both the effects and causes of aging in model organisms can yield valuable insight into the molecular and cellular processes that underlie aging in humans.

Various model systems, including yeast, C. elegans, and rodents have been used to study the processes regulating organismal longevity. Drosophila also has many advantages to studying the biology of aging. For example, flies represent an optimal compromise between physiological, genetic, and anatomical relevance to humans as well as genetic, physiological, behavioral, and demographic power (Boulianne, 2001; Reiter et al., 2001; Helfand and Rogina, 2003; Jafari et al., 2006; Iliadi and Boulianne, 2010). Fruit flies also have a number of strengths that specifically aid in studies of aging and longevity. For example, while the lifespan of flies is relatively short (60-80 days), flies still exhibit age-related decline in several behaviors (Grotewiel et al., 2005). Furthermore, the demarcation between development and adulthood is much clearer in insects than other model organisms (adulthood being defined as eclosion from the pupal case). Large brood sizes also make it possible to measure survival in large numbers of individuals within each experimental cohort in controlled environments and to test the functional consequences of senescence either longitudinally in individuals or as sampled from the aging population. Finally, since most cells in adult flies are postmitotic (except a few cells in the gut, malpighian tubules, and gonads), the age-related decline in cellular function can be examined without interference from newly dividing cells. In this review, we will discuss how studies in Drosophila can provide insight into the mechanisms regulating healthy aging.

\section{PHYSIOLOGY OF SENESCENCE}

Aging is a universal process and all species studied show age-related functional declines. However, different species age at different rates likely due to different fitness strategies employed to survive and reproduce in a competitive environment. The rate of aging can also be quite variable between individuals of a given species. Furthermore, while all cells, tissues, and organs show a functional decline over time, not all tissues experience aging at the same rate. Some systems may change slowly, while others decline rapidly, and some may even show periods of increased function (Spirduso et al., 2005). Despite the extensive variability both between species, and within individuals, several tissues exhibit physiological senescence in both invertebrates and mammals, including a decline in muscle strength (Nair, 2005; Augustin and Partridge, 2009; Demontis and Perrimon, 2010), immune response (Hoffmann, 2003; Flajnik and Du Pasquier, 2004), stress resistance (Service et al., 1985; Rose, 1999; Murakami, 2006), reproduction (te Velde and Pearson, 2002; Novoseltsev et al., 2005; Tatar, 2010; Luo and Murphy, 2011), and cognition (Horiuchi and Saitoe, 2005; Grady, 2008).

\section{AGING, MUSCLE STRENGTH, AND LOCOMOTOR FUNCTION}

Sarcopenia or loss of muscle mass and function, is perhaps one of the most marked problems associated with aging and has been described for both invertebrates and higher organisms (Fisher, 2004; Augustin and Partridge, 2009). At the cellular level, this disease reflects mitochondrial dysfunction, altered apoptotic and autophagic signaling, as well as trace metal dyshomeostasis (Marzetti et al., 2009). Morphologically, sarcopenia is characterized by a decrease in both the number and size of individual fibers (Larsson et al., 1978) and an increase in the extracellular space and deposition of protein aggregates within the interstitial matrix (Kim et al., 2008). Despite the fact that Drosophila and human muscles show essential differences in fiber type, innervation, and regeneration, they both exhibit age-related morphological and functional changes. For example, myofibrils of old flies display reduced sarcomere length, increased in vivo interfilament spacing, and increased lattice disorder, showing a loss of ultrastructural integrity and acute sarcopenia (Miller et al., 2008). Interestingly, heart muscle structure and cardiac performance are also progressively impaired with age in flies (Nishimura et al., 2011).

Additionally, recent studies in flies have indicated a role for the well-known longevity-regulating pathways in the coordination of muscle aging. For example, the activation of $\mathrm{dFOXO}$ and its target $4 \mathrm{E}-\mathrm{BP}$ in muscle decelerates aging and reduces the agerelated accumulation of protein aggregates, whereas foxo mutants accelerate loss of proteostasis (Demontis and Perrimon, 2010). RNAi-mediated knockdown of the mitochondrial superoxide dismutase 2 (SOD2) in muscle tissue decreases locomotion and shortens lifespan (Martin et al., 2009). Likewise, results from another study have shown that overexpression of p38 MAP kinase extends Drosophila lifespan in a MnSOD-dependent manner while inhibition leads to early lethality and accelerates age-related motor (muscle-restricted) dysfunction (Vrailas-Mortimer et al., 2011).

Behavioral locomotion assays can offer an accurate way of assessing changes in muscle function. In Drosophila, many studies have shown that motor functions are significantly reduced with aging (Le Bourg and Lints, 1984; Fernandez et al., 1999; Simon et al., 2006; Martinez et al., 2007; Rhodenizer et al., 2008). Among various available methods for the assessment of locomotor activity, the startle-induced climbing behavior (negative geotaxis) is a reliable and informative assay. Usually, in these experiments, flies are tapped down to the bottom of their test vial and the distance the flies climb up the vial within a particular period of time is measured. This assay measures a whole complex of different behaviors including the escape reflex in response to mechanical stress, negative geotaxis (an inner orienting response and movement in opposition to gravitational cues), climbing ability, and locomotor activity itself. All of these behaviors reflect the functional status of muscle and locomotor function to varying degrees. Interestingly, detailed studies have revealed that the age-related decline in performance does not depend on the density of animals in the 
test vial or the housing conditions (Cook-Wiens and Grotewiel, 2002; Goddeeris et al., 2003) but rather is primarily due to an age-dependent decrease in locomotor speed (Rhodenizer et al, 2008) similar to that seen in humans, suggesting a conserved mechanism. The relative simplicity and reproducibility of these behavioral assays makes locomotor activity a useful biomarker for healthy aging.

\section{AGE-SPECIFIC IMMUNE RESPONSE}

The aging of an organism is accompanied by weakening of both the acquired and innate immune response (immunosenescence) to a wide range of pathogens. This process is mainly characterized by a gradual depression of cellular function throughout the immune system that, not only decreases immune response, but can also provoke the development of autoimmune disorders (Prelog, 2006). The innate immune response represents the first line of defense, comprising multiple pathways and systems, which are functionally conserved in both vertebrates and invertebrates (Flajnik and Du Pasquier, 2004). In Drosophila an innate immune response consists of several general components including pathogen detection via receptors that activate the Toll or Imd (Immune deficiency) signaling pathways (De Gregorio et al., 2002), hormonal regulation by means of juvenile and 20-hydroxy-ecdysone hormones that antagonistically induce antimicrobial peptide genes (Flatt et al., 2008a), prophenoloxidase cascade resulting in melanization (encapsulation of pathogens) (Tang, 2009), and cellular events such as phagocytosis (Williams, 2007). In contrast, acquired or adaptive immunity is an antigen-specific response that lasts a very long time and can generate "immune memory" to protect an organism against re-exposure to the same antigens. This type of response has been described for vertebrates and represents the second line of defense that is initiated when the non-specific, innate immune response is unable to deal with an invading pathogen.

Several studies suggest that aging has a profound effect on the status of the immune system in insects. For example, reduced phenoloxidase activity was observed in aged bumblebees (Whitehorn et al., 2011) and crickets (Adamo, 2004). Adult scorpionflies show a dramatic decrease in phagocytic capacity with age, even though cell numbers remained fairly constant (Kurtz, 2002). To date, the majority of studies in Drosophila have focused on the analysis of genes that exhibit age-related transcriptional changes. Interestingly, the most striking genome-wide (Pletcher et al., 2002; Landis et al., 2004; Sarup et al., 2011) and body-wide (Seroude et al., 2002) age-related increase in expression was found for genes that are involved in the immune response. However, it is unclear why immune response genes are up-regulated during aging. One possible explanation is that organisms increase their expression of immune related genes in response to prolonged exposure to pathogens throughout their life. Alternatively, it may reflect the decline in functional capacity of innate immunity with age (Zerofsky et al., 2005; Ramsden et al., 2008; Sarup et al., 2011).

Studies such as these may be useful for identifying potential biomarkers of immunosenescence, although additional microarray and proteomic studies will be required to identify novel markers and validate genes/proteins previously shown to exhibit agerelated expression changes following infection or in the absence of infection. Additional studies will also facilitate the development of appropriate molecular biomarkers of immunosenescence and the possible discovery of a completely novel mechanism that does not involve any of the genes/pathways identified to date. Another approach is to use cellular immunity biomarkers such as hemocytes. In adult flies, hemocytes either freely float within the hemolymph or are sessile (Williams, 2007). They are primarily specialized for phagocytosis and encapsulation. In a recent study, Mackenzie et al. (2011) compared the numbers and activity of the circulating hemocytes in flies of different ages. They found that the hemocyte population, which is responsible for clearing microbes from the hemocoel, becomes less able to phagocytose microbes with age due to fewer cells with phagocytic activity. The number of circulating hemocytes in females also significantly declined with age. Given the similarity between plasmatocyte hemocytes in adult Drosophila and the monocyte lineage that gives rise to macrophages in vertebrates, coupled with the relative simplicity of these measurements, this method has the potential to be a valid way of monitoring healthy aging of the fly immune system. Furthermore, using techniques such as this to analyze age-specific survival and the ability to protect against, and clear infection, will improve our understanding of which components of the immune system are responsible for immunosenescence.

\section{AGING AND STRESS RESISTANCE}

The rate of living theory is probably the oldest among theories of aging (Pearl, 1928). Pearl formulated his theory based on Rubner's observation of a negative relationship between metabolic rate, body size, and longevity. Pearl's theory postulated that the lifespan of an organism is related to its metabolic rate; such that individuals (within a given species) with a higher metabolic rate (high level of energy consumption) will have a shortened lifespan compared to individuals with a lower rate. Consistent with this theory, observations in Drosophila melanogaster and Musca domestica, showed that flies raised at lower ambient temperatures have a lower level of metabolic activity and much longer lifespan compared to flies raised at higher temperatures (Miquel et al., 1976; Sohal, 1986; Farmer and Sohal, 1987). The association between metabolic rate and lifespan was also supported by artificial selection experiments (Riha and Luckinbill, 1996; Arking et al., 2002). Although this theory is not universally accepted (Austad and Fischer, 1991; Speakman et al., 2004; Van Voorhies, 2004) it nevertheless formed the basis for a free radical theory of aging (Harman, 1956). According to Harman's theory, free radicals, produced as a by-product of oxidative phosphorylation can damage important biological molecules. Accumulation of this damage over time, accounts for the effects of aging and eventually leads to death. The reactive oxygencontaining species (ROS) can covalently modify biomolecules such as nucleic acids, proteins, and lipids and cause oxidative stress. The level of this stress is determined by the misbalance between the production of ROS on the one hand and the efficiency of the antioxidant defense and repair processes on the other hand. Several studies in Drosophila have shown that flies selected for extended longevity exhibit resistance to oxidative stress (Service et al., 1985; Arking et al., 1991). In healthy cells, resistance to oxidative stress is accomplished by means of a complex defense system consisting of both enzymatic and non-enzymatic components, the main role of which is to breakdown and/or to neutralize ROS. This 
defense complex includes superoxide dismutases $(\mathrm{Cu} / \mathrm{Zn}$ SOD and MnSOD), catalase (cat), and glutathione-peroxidase. Firstly, superoxide dismutases convert superoxide to hydrogen peroxide and then catalase and glutathione-peroxidase remove the hydrogen peroxide from the intracellular environment by converting it to water. It is thought that these defense mechanisms become less efficient with aging and in some disease conditions, and ROS damage accumulates within cells in the form of chromosomal aberrations, membrane destabilization, loss of essential protein function, and ATP depletion. In humans, damage caused by ROS is not only thought to contribute to the aging process but has also been linked to numerous neurodegenerative diseases such as Amyotrophic Lateral Sclerosis (Robberecht, 2000) and Alzheimer's disease (Smith et al., 2000).

Several selection experiments have shown that some long-lived Drosophila strains express higher than normal levels of SOD (Tyler et al., 1993; Dudas and Arking, 1995; Hari et al., 1998). Interestingly, reverse selection of the long-lived flies for short lifespan restores antioxidant gene expression to control levels (Arking et al., 2000). Studies of the effect of single gene mutations that affect the lifespan of flies may also serve as a confirmation of the relationship between aging and resistance to stress. For example, reduced expression of methuselah (encoding a G protein-coupled receptor), causes a significant increase in lifespan and resistance to a number of stresses including starvation, high temperature and paraquat (Lin et al., 1998). In contrast, mutations that affect genes involved in ROS defense such as SOD or catalase have a negative impact on lifespan and show hypersensitivity to a variety of agents that generate ROS including $\mathrm{Cu}^{2}$, paraquat, ionizing radiation, and hyperoxia (Campbell et al., 1986; Mackay and Bewley, 1989; Phillips et al., 1989). The relationship between oxidative stress and lifespan has also been illustrated by overproducing ROS protective enzymes. Using an inducible expression system based on the FLP recombinase; Tower and colleagues found a positive effect of SOD overexpression on Drosophila lifespan (Sun and Tower, 1999; Tower, 2000). A similar effect was seen when human SOD was overexpressed in motorneurons (Parkes et al., 1998). Remarkably, the extension of lifespan did not change the overall metabolic rate of the flies, suggesting that the observed effect was due to increasing oxidative stress resistance. Lifespan was also extended by simultaneous overexpression of SOD and catalase (Orr and Sohal, 1994). Transgenic flies which overexpress these two tandem acting enzymes exhibited a one-third extension of lifespan as well as reduced oxidative damage and a delayed loss of locomotor activity.

Despite the above examples, it is unclear whether the activity of antioxidant enzymes is required to extend lifespan. For example, the activity of several antioxidant enzymes were essentially the same in Drosophila lines selected for long or short lifespan. Similarly, the glutathione content (Mockett et al., 2001), SOD allele frequency (Force et al., 1995), and the electrophoretic mobility of SOD enzymes (Luckinbill et al., 1989), were also similar in short and long-lived lines. Furthermore, other studies showed that transgenic manipulations of antioxidant enzyme expression had little or no effect on lifespan (Seto et al., 1990; Reveillaud et al., 1991; Orr and Sohal, 1992, 1993; Orr et al., 2003). These discrepancies may be explained by differences in genetic background, the level of transgene expression, the experimental methodologies used and/or the lack of adequate controls. Overall, these studies suggest that antioxidant defense may not be essential for lifespan extension but rather play a primary role in healthy aging. Unfortunately, there are only a few studies that report the functional consequences of manipulating the levels of antioxidant enzymes in Drosophila. Nevertheless, several facts appear to indicate that antioxidant defense affects healthy aging. First, in those studies where behavioral analysis was reported, the increased or reduced/abolished antioxidant enzyme activity was associated with delayed or accelerated functional senescence, respectively (Orr and Sohal, 1994; Ruan et al., 2002; Piazza et al., 2009; Hirano et al., 2012). Second, increased antioxidant enzyme activity increases stress resistance while reduced/abolished activity has the opposite effect, in most studies (see Le Bourg, 2001b for details). Third, the positive effect of increased antioxidant expression on lifespan tends to be most apparent in short-lived genetic backgrounds. Using data from all published studies examining overexpression of antioxidant enzymes, Orr and Sohal (2003) found a clear negative correlation between lifespan extension with overexpression of the antioxidant enzymes and the lifespan of controls. It seems that when an organism is "genetically" under great stress, the enhancement of its antioxidative defense properties can have a beneficial (rescue) effect whereas, under optimal conditions including optimal (wild type) genetic background such enhancement is less effective or even ineffective. Finally, the progression and severity of many age-related pathologies and diseases can be increased or diminished through modulation of the expression of genes involved in oxidative defense. Salmon et al. (2010) summarized the data showing that healthspan rather than lifespan is strongly affected by antioxidant status. Altogether, the data suggests that resistance to oxidative stress can be used as an indicator of healthy aging.

\section{AGING, SEXUAL BEHAVIOR, AND REPRODUCTION}

From an evolutionary point of view, there is no doubt that a higher level of reproductive success positively contributes to total fitness (Ehrman and Parsons, 1981). At the same time, life history theory (antagonistic pleiotropy) proposes that higher levels of reproduction are negatively correlated with survival (Williams, 1957). This so-called "cost of reproduction" concept has been widely accepted and demonstrated in a number of experimental studies (see reviews; Rose and Bradley, 1998; Partridge et al., 2005; Flatt and Promislow, 2007; Tatar, 2010). For example, selection experiments in Drosophila have shown that direct selection for extended longevity decreases early reproduction (Zwaan et al., 1995), while selection for postponed reproduction leads to increased longevity (Rose, 1991; Partridge et al., 1999). Female flies sterilized by either irradiation or by the sterile ovo ${ }^{D}$ mutation have reduced agerelated mortality (Sgro and Partridge, 1999). However, several experiments have cast doubt on the relationship between lifespan and fecundity. Using Drosophila mutants that lack a proliferating germ line, Barnes et al. (2006) have shown that life-long germ line ablation reduced longevity in females and either had no effect, or gave rise to a slight extension of longevity in males. In a similar study, loss of germ cells late in development or in the adult extends lifespan and modulates components of insulin/insulinlike growth factor signaling in Drosophila (Flatt et al., 2008b) and 
C. elegans (Arantes-Oliveira et al., 2002). Examination of lifespan in various mutant or transgenic animals, also argue against a direct cost of reproduction on lifespan. In C. elegans, mutations in the age- 1 and daf- 2 genes result in life extension, without changes in reproductive ability (Johnson et al., 1993; Gems et al., 1998). In Drosophila, females bearing mutations in either the insulin-like receptor gene (Tatar et al., 2001), or the insulin-receptor substrate chico (Clancy et al., 2001), show decreased fertility and increased lifespan consistent with the cost of reproduction theory. However, the extended longevity and reduced fecundity appear to be unrelated since in combination with the dominant sterile mutation ovo ${ }^{D}$ (which blocks oogenesis and extends female lifespan), chico mutant flies do not live as long as either fertile chico heterozygotes or sterile homozygotes (Clancy et al., 2001). Interestingly, several long-lived lines, including Indy mutants (Marden et al., 2003), ecdysone receptor mutants (Simon et al., 2003), or flies overexpressing the transcription factor $d F O X O$ in adult head fat body (Hwangbo et al., 2004), do not exhibit reduced fecundity and, in some cases, have even shown an increase for these traits. It has been demonstrated in a series of Drosophila behavioral experiments, that sexual behavior and mating itself may have a profound negative impact on lifespan. For example, males that were supplied daily with virgin females showed decreased lifespan (Partridge and Farquhar, 1981). In females, mating reduces lifespan (Fowler and Partridge, 1989), possibly as a result of the competitive reallocation of limited physiological resources for courtship and egg production (Partridge et al., 1987), or from toxic peptides transferred to females in male seminal fluid (Chapman et al., 1995). However, it is unclear whether all of these factors are relevant in nature. For example, most females in nature are fertilized. They actively reject male courtship in many different ways including decamping behavior (running away, jumping, and flying away from the courting male) that may lead to full loss of contact with the courting male. In addition, female egg production and egglaying rates greatly depend on ecological context, such as weather and climatic conditions, food availability, and the presence of predators.

In humans, the relationship between longevity and reproduction have been addressed in numerous studies, however, the results have yielded even more conflicting conclusions. The majority of these studies were focused on validation of The Disposable Soma Theory of Aging. One of the basic principles Kirkwood's evolutionary theory is that aging occurs as a result of decreased investment of resources in somatic maintenance and repair, to allow for increased allocation of resources toward reproduction (Kirkwood, 1977). This theory was tested using historical data sets collected from the British aristocracy living from the eighth to the nineteenth century (Westendorp and Kirkwood, 1998). It was shown that both the longevity of women, living at least up to 50 years (i.e., after the end of their reproductive life) and the longevity of men were negatively correlated with fertility. Thus, the authors came to the conclusion that these results confirm the existence of a trade-off between longevity and fertility in humans. While this study had a large resonance in the scientific and public press, it has been severely criticized (Gavrilov and Gavrilova, 1999; Le Bourg, 2001a; Gavrilova and Gavrilov, 2005; Mitteldorf, 2010) primarily because of the quality of the database and inadequate statistical approach. In another study, using data from 153 countries, a highly significant positive correlation was observed between lifespan and fecundity (Thomas et al., 2000). Also, in a more detailed genealogical analysis of British aristocrats, a significant correlation between human lifespan and fertility was found when the effects of health and of mortality selection during childbearing ages were considered (Doblhammer and Oeppen, 2003). There are many additional reports that indicate a positive (Muller et al., 2002; McArdle et al., 2006) or inconclusive association (Le Bourg et al., 1993; Lycett et al., 2000) between lifespan and fertility in humans (see also Gavrilova and Gavrilov, 2005 for historical review of the relevant studies). Le Bourg (2007), in his comprehensive review summarizes most of the available data and concludes that, at present, there is insufficient evidence to conclude that longevity requires limited resources to be invested in somatic maintenance, thus reducing the availability of resources for reproduction. In fact, as the author points out, even if a relationship between these variables does exist, it depends more on the population under study than on a general mechanism linking longevity and fertility.

Aging has a negative impact on sexual activity and reproductive function for both sexes. Age-related decline in these functions is caused by numerous physiological changes particularly in the neuroendocrine and reproductive systems. In women these changes are mainly manifested in the reduction in follicle number and ovarian function and, as a consequence, in reduced secretion of estrogens and progesterone (Djahanbakhch et al., 2007). In men, the progressive decline in sexual function is accompanied by changes in levels of testosterone and associated reproductive hormones (Murray and Meacham, 1993). There is a fundamental difference between reproductive senescence in men and women. Women, show an abrupt loss of reproductive potential that marks the end of their "reproductive life," while in men, reproductive function declines more gradually and does not involve an acute drop in fertility.

In contrast to humans, Drosophila females continue to produce primary oocytes from stem or progenitor cells throughout their life, reaching a maximum in young females and followed by a steady decline (Novoseltsev et al., 2005). The quality of eggs or level of fertilization is also affected by age (David et al., 1975). Interestingly, detailed analysis of female reproductive senescence revealed that Drosophila egg-laying and mortality rates were dependent on mating history (Rogina et al., 2007). Female reproductive life can be divided into three epochs: optimal, vulnerable, and declining terminal. The first epoch of adulthood is characterized by a high rate of egg-laying after mating and has a reversible effect on mortality. During the second epoch, mating does not induce increased egg-laying but does result in an irreversible increase in mortality. Finally, at the terminal stage, females exhibit sharp reductions in egg-laying regardless of their chronological age. Despite the differences between flies and humans as to the effect of age on reproductive behavior, there may be some parallels between the processes that occur in follicles of aging humans and in egg chambers of aged flies under oxidative stress (Tatar, 2010). Cumulative oxidative damage caused by free radicals was suggested to impair the viability of developing follicles in humans (Tatone et al., 2008). In Drosophila, overexpression 
of the antioxidant enzyme SOD in germ line stem cells leads to increased numbers of these cells in aged females (Pan et al., 2007).

Drosophila males exhibit a peak of sexual activity up to 4 weeks. During this period they show a fairly constant performance in such traits as multiple mating, latency time, duration of copulation, and level of fertility. These characteristics decline in a manner that is similar to the age-dependent course of survivorship (Economos et al., 1979). Male reproductive success can be measured either under competitive or non-competitive mating conditions. Selection for delayed senescence increased the male reproductive success in both competitive and noncompetitive conditions. This selection also resulted in significant increases in the ability to recover from exhaustive mating bouts (Service, 1993). Several components of male reproductive behavior show a clear age-dependent decline including the time to begin copulation, duration of copulation, and the proportion of females that were remated (Service, 1993). Moreover, males that had been subjected to selection for delayed senescence were superior to control males (rapid senescence) with regards to one of the components, sperm competition (sperm defense).

Overall, the peculiarities of Drosophila reproductive history allow us to conclude that fruit flies exhibit obvious senescence in reproductive functions. The progression of senescence can be monitored by measuring the age-related changes in sexual and reproductive behaviors. Delay in reproductive senescence may contribute to the general extension of lifespan, which is more important in healthy aging.

\section{SENESCENCE OF COGNITIVE FUNCTION}

The gradual impairment of cognitive function is one of the main components of the normal aging process. Age-related decline in cognitive function may vary considerably between individuals and in the cognitive processes affected such as attention, memory, or decision-making. Progressive impairment of cognitive function is frequently associated with age-related degenerative brain disorders such as different types of dementia, including Alzheimer's and Huntington's disease, vascular and Parkinson's dementia, and Lewy body disease. These diseases are becoming more and more common amongst aged people across the globe and represent a growing clinical and social issue.

Attention is a key cognitive process that affects virtually all other cognitive functions. For example, it has been suggested that attentive processes may be involved in orientation, concentration, and filtration of distracting information (McDowd and Shaw, 2000). Older people usually have some difficulties with attention tasks that require dividing or switching of attention between multiple inputs (Verhaeghen and Cerella, 2002). An early symptom of Alzheimer's disease also involves problems with selective attention. Specifically, Alzheimer's patients exhibit a proportionally greater deficit in inhibitory and visual search tasks (Levinoff et al., 2004) as well as in tasks that require the inhibition of automatic cognitive ability (Perry et al., 2000).

Memory impairments are among the most commonly recognized cognitive changes in senescent humans. They arise from defects in the encoding, storage, and retrieval of information. In general, these defects can be classified into several major groups: (1) "sensory memory" - retains information only long enough to operate on it (object recognition), and requires the contribution of different sensory inputs; (2) "working memory" also known as "short-term memory" - actively holds new information in the mind allowing temporal tasks such as reasoning and comprehension to be performed, and is required for further information processing; (3) "long-term memory" - where information can be essentially stored for a lifetime. Working memory is impaired in old age (Hertzog et al., 2003; Oberauer et al., 2003), however, the mechanisms underlying this impairment are still under debate. Loss of long-term memory in aged humans may be associated with a number of causes. First of all, there are several differences between the long-term memory defects observed during normal aging and those that are associated with some pathological conditions. In normal aging, the memory defects are mainly the result of inconsistent encoding and retrieval strategies, whereas pathologies such as Alzheimer's disease, are characterized by a selective and severe deterioration in the consolidation and storage of new information. In other words, in normal age-related memory loss, individuals may express a sense of frustration due to an inability to recall specific memories, while in Alzheimer's disease patients forget the memory entirely, including the context in which the memory was formed.

Evidence from a wide range of cross-sectional studies suggests that many of the individual differences in age-related cognitive function are associated with differences in sensory function such as hearing or sight. Moreover, when this variance in sensory function is statistically controlled, the differences in cognitive function disappear (Baltes and Lindenberger, 1997). Many cognitive processes such as problem solving, goal-directed behavior, and decisionmaking require the integration and processing of information from numerous primary inputs for its effective performance.

The study of learning and memory in fruit flies began in the laboratory of Seymour Benzer more than three decades ago. Using chemical mutagenesis approaches coupled with a reliable method designed to specifically induce learning and memory, several mutants were isolated (Quinn et al., 1974). Studies of these mutants have provided insight into the cellular and biochemical mechanisms underlying learning and different kinds of memory formation (Dubnau and Tully, 1998). Flies have multimodal sensory modalities that gather information about the external world and translate it by means of the nervous system into an appropriate behavioral response. In fact, flies possess a large number of sensory organs that result in the perception of taste, touch, smell, hearing, and vision (Stocker, 2004; Ebbs and Amrein, 2007; Gerber and Stocker, 2007; Kernan, 2007; Ting and Lee, 2007). Many studies clearly demonstrate that fruit flies are capable of both associative and non-associative learning and memory. For example, flies can learn to move toward odors previously associated with reward, or avoid an odor that has been paired with punishment (Tempel et al., 1983; Tully and Quinn, 1985). They can also learn to recognize different visual, tactile, and spatial cues (Wustmann and Heisenberg, 1997; Heisenberg et al., 2001). Interestingly, Drosophila males show a plasticity in courtship behavior, through a complex process that may include habituation, sensitization, 
operant, and classical learning (Siegel and Hall, 1979; Kamyshev et al., 1999; Griffith and Ejima, 2009). Several recent studies have shown that flies may demonstrate attention-like (van Swinderen, 2007), goal-driven (Pick and Strauss, 2005), and decision-making behaviors (Zhang et al., 2007). To date, Drosophila has also been successfully used as a model system to reveal molecular, physiological, and behavioral mechanisms of several human neurodegenerative diseases, including Alzheimer's, Parkinson's, and Huntington's (Chan and Bonini, 2000; Lu, 2009; Bonner and Boulianne, 2011).

Similar to other organisms, Drosophila exhibit age-related reductions in learning ability and memory performance. In early studies, Le Bourg (1983) investigated the role of age on nonassociative learning using a proboscis extension reflex (PER). This reflex represents a stereotyped response to the activation of chemoreceptors located on the foreleg tarsi by sucrose. Repeated application of sucrose caused habituation to the stimulus whereby the fly stopped extending its proboscis in response to application. In this study, flies did not show any age-related effect on habituation as measured either by the percentage of flies that were able to habituate or the number of training sessions required for habituation. Aged individual flies showed impairment in habituation, specifically in the speed of memory acquisition in this learning task (Fois et al., 1991). Decrease in learning performance was observed between 3 and 35 days, and reached a plateau after 35 days. In another paradigm, the conditioned suppression of PER, flies learned to associate sucrose stimulation with negative reinforcement (Brigui et al., 1990). Both middle-aged and old flies required more training to associate the positive and negative stimuli. Age-dependent effects on PER were also observed in a visual discrimination task. The acquisition of PER suppression was delayed in middle-aged and old flies (Fresquet and Medioni, 1993). Age-related memory impairment in flies was also observed using a Pavlovian olfactory avoidance paradigm (Tamura et al., 2003). In this paradigm, flies learn to associate an electric shock with an odor. Depending on the training regimen induced, memory may persist either for minutes (short-term memory), hours (short and middle-term memory), or even days (long-term memory). Flies exhibited a weak reduction in immediate memory performance (right after training) by about 10 days of age, which did not progress up to the age of 50 . However, short-term memory was severely impaired in 20 day old flies and declined to a minimum up to the age of 50 days. Interestingly, aging has differential effects on distinct memory forms. For example, old and young flies perform comparably with respect to protein synthesis-independent anesthesia resistant memory, while the protein synthesis dependent long-term memory is completely abolished in old flies (Mery, 2007).

Several studies on Drosophila learning and memory mutants confirm that not all forms of memory are equally affected by age. For example, young amnesiac (middle-term memory mutant) flies show similar memory retention to aged wild type flies (Tamura et al., 2003). Expression of this gene does not decrease with age and its overexpression does not suppress age-related memory impairment in a wild type background (Saitoe et al., 2005). Another memory mutant, $D C O$, delays age-related memory impairment without altering lifespan and memory at early ages (Yamazaki et al.,
2007). Another method to induce and test learning and memory in flies is conditioned courtship suppression, where male flies learn to attenuate their courtship behavior after a negative experience of courting a fertilized female. This paradigm is based on natural sexual behavior and involves only natural stimuli such as visual and olfactory (pheromones) cues. Interestingly, 30-day-old wild type flies do not show a significant decrease in immediate or short-term memory with this assay, whereas mutants in the kynurenine pathway do (Savvateeva et al., 1999). Thus, natural selection may favor the maintenance of some specific forms of memory in aged flies. Taken together, these studies demonstrate that Drosophila can be utilized to identify and characterize the effect of age and the role of single genes in learning and memory and provide insight into core mechanisms of cognitive senescence in many species including humans.

\section{CONCLUSION}

It is well-known that advances in medicine and health care have significantly contributed to increased longevity in humans over the last 100 years. There is also a clear trend toward increased life expectancy including an increase in the numbers of people living to an advanced age and the number of people with chronic agerelated diseases. These trends emphasize the need to understand the genetic and physiological factors underlying biological aging and particularly, those that promote healthy aging.

According to Arking (2003) there are three ways to extend lifespan: increasing early survival rate, increasing late survival rate, or delaying senescence. Remarkably, the first two do not affect basic aging processes. For example, the first one leads to a significant increase in mean but not maximum lifespan, while the second one leads to change in a maximum but not mean lifespan. Delayed senescence, in turn, leads to a significant increase in both the mean and maximum lifespan (Arking, 2005). This raises the question as to whether healthspan and delayed senescence are inter related. As stated above, while many genes have been shown to extend lifespan, these may have little or no ability to delay physiological senescence. In other words, the period of functional disability before death may increase despite the fact that the total duration of life is increased. Thus, the search for appropriate biomarkers applicable to monitor functional senescence is highly important with regards to healthy aging and age-related diseases.

Finally, it is likely that not all senescent physiological changes revealed in flies can be simply translated to humans. However, flies and humans often show very similar age-related physiological phenotypes suggesting that at least some of the basic biological properties and mechanisms that regulate longevity are conserved amongst species. Clearly, future studies focusing on mechanisms that promote healthy aging rather than lifespan extension could have significant impact on our elderly population and those suffering from age-related disorders.

\section{ACKNOWLEDGMENTS}

This work was supported by a grant to Gabrielle L. Boulianne from the Canadian Institutes of Health Research (CIHR; MOP 14143). Gabrielle L. Boulianne is the recipient of a Tier 1 Canada Research Chair in Molecular and Developmental Neurobiology. 


\section{REFERENCES}

Adamo, S. A. (2004). Estimating disease resistance in insects: phenoloxidase and lysozyme-like activity and disease resistance in the cricket Gryllus texensis. J. Insect Physiol. 50, 209-216.

Arantes-Oliveira, N., Apfeld, J., Dillin, A., and Kenyon, C. (2002). Regulation of life-span by germ-line stem cells in Caenorhabditis elegans. Science 295, 502-505.

Arking, R. (2003). Aging: a biological perspective. Am. Sci. 91, 508-515.

Arking, R. (2005). Multiple longevity phenotypes and the transition from health to senescence. Ann. N. Y. Acad. Sci. 1057, 16-27.

Arking, R., Buck, S., Berrios, A., Dwyer, S., and Baker, G. T. III. (1991). Elevated paraquat resistance can be used as a bioassay for longevity in a genetically based long-lived strain of Drosophila. Dev. Genet. 12, 362-370.

Arking, R., Buck, S., Hwangbo, D. S., and Lane, M. (2002). Metabolic alterations and shifts in energy allocations are corequisites for the expression of extended longevity genes in Drosophila. Ann. N. Y. Acad. Sci. 959, 251-262; discussion 463-465.

Arking, R., Burde, V., Graves, K., Hari, R., Feldman, E., Zeevi, A., Soliman, S., Saraiya, A., Buck, S., Vettraino, J., Sathrasala, K., Wehr, N., and Levine, R. L. (2000). Forward and reverse selection for longevity in Drosophila is characterized by alteration of antioxidant gene expression and oxidative damage patterns. Exp. Gerontol. 35, 167-185.

Augustin, H., and Partridge, L. (2009). Invertebrate models of age-related muscle degeneration. Biochim. Biophys. Acta 1790, 1084-1094.

Austad, S. N., and Fischer, K. E. (1991). Mammalian aging, metabolism, and ecology: evidence from the bats and marsupials. J. Gerontol. 46, B47-B53.

Baltes, P. B., and Lindenberger, U. (1997). Emergence of a powerful connection between sensory and cognitive functions across the adult life span: a new window to the study of cognitive aging? Psychol. Aging 12, 12-21.

Barger, J. L., Walford, R. L., and Weindruch, R. (2003). The retardation of aging by caloric restriction: its significance in the transgenic era. Exp. Gerontol. 38, 1343-1351.

Barnes, A. I., Boone, J. M., Jacobson, J., Partridge, L., and Chapman, T. (2006). No extension of lifespan by ablation of germ line in Drosophila. Proc. Biol. Sci. 273, 939-947.

Bluher, M., Kahn, B. B., and Kahn, C. R. (2003). Extended longevity in mice lacking the insulin receptor in adipose tissue. Science 299, 572-574.

Bonner, J. M., and Boulianne, G. L. (2011). Drosophila as a model to study age-related neurodegenerative disorders: Alzheimer's disease. Exp. Gerontol. 46, 335-339.

Boulianne, G. L. (2001). Neuronal regulation of lifespan: clues from flies and worms. Mech. Ageing Dev. 122, 883-894.

Brigui, N., Le Bourg, E., and Medioni, J. (1990). Conditioned suppression of the proboscis-extension response in young, middle-aged, and old Drosophila melanogaster flies: acquisition and extinction. J. Comp. Psychol. 104, 289-296.

Campbell, S. D., Hilliker, A. J., and Phillips, J. P. (1986). Cytogenetic analysis of the cSOD microregion in Drosophila melanogaster. Genetics 112, 205-215.

Chan, H. Y., and Bonini, N. M. (2000). Drosophila models of human neurodegenerative disease. Cell Death Differ. 7, 1075-1080.

Chapman, T., Liddle, L. F., Kalb, J. M., Wolfner, M. F., and Partridge, L. (1995). Cost of mating in Drosophila melanogaster females is mediated by male accessory gland products. Nature 373, 241-244.

Clancy, D. J., Gems, D., Harshman, L. G., Oldham, S., Stocker, H., Hafen, E., Leevers, S. J., and Partridge, L. (2001). Extension of life-span by loss of CHICO, a Drosophila insulin receptor substrate protein. Science 292, 104-106.

Cook-Wiens, E., and Grotewiel, M. S. (2002). Dissociation between functional senescence and oxidative stress resistance in Drosophila. Exp. Gerontol. 37, 1347-1357.

David, J., Cohet, Y., and Foluillet, P. (1975). The variability between individuals as a measure of senescence: a study of the number of eggs laid and the percentage of hatched eggs in the case of Drosophila melanogaster. Exp. Gerontol. 10, 17-25.

De Gregorio, E., Spellman, P. T., Tzou, P., Rubin, G. M., and Lemaitre, B. (2002). The toll and Imd pathways are the major regulators of the immune response in Drosophila. EMBO J. 21, 2568-2579.

Demontis, F., and Perrimon, N. (2010). FOXO/4E-BP signaling in Drosophila muscles regulates organism-wide proteostasis during aging. Cell 143, 813-825.

Djahanbakhch, O., Ezzati, M., and Zosmer, A. (2007). Reproductive ageing in women. J. Pathol. 211, 219-231.

Doblhammer, G., and Oeppen, J. (2003). Reproduction and longevity among the British peerage: the effect of frailty and health selection. Proc. Biol. Sci. 270, 1541-1547.

Doriansky, J. P., Suzman, R. M., and Hodes, R. J. (2007). "Why population aging matters: a global perspective," eds R. M. Li, A. C. Iadarola, and C. C. Maisano. Available at: http://www.nia.nih.gov/res earch/publication/why-populationaging-matters-global-perspective

Dubnau, J., and Tully, T. (1998). Gene discovery in Drosophila: new insights for learning and memory. Annu. Rev. Neurosci. 21, 407-444.

Dudas, S. P., and Arking, R. (1995). A coordinate upregulation of antioxidant gene activities is associated with the delayed onset of senescence in a long-lived strain of Drosophila. J. Gerontol. A Biol. Sci. Med. Sci. 50, B117-B127.

Ebbs, M. L., and Amrein, H. (2007). Taste and pheromone perception in the fruit fly Drosophila melanogaster. Pflugers Arch. 454, 735-747.

Economos, A. C., Miquel, J., Binnard, R., and Kessler, S. (1979). Quantitative analysis of mating behavior in aging male Drosophila melanogaster. Mech. Ageing Dev. 10, 233-240.

Ehrman, L., and Parsons, P. A. (1981). Sexual isolation among isofemale strains within a population of Drosophila immigrans. Behav. Genet. 11, 127-133.

Farmer, K. J., and Sohal, R. S. (1987). Effect of ambient temperature on free radical generation, antioxidant defenses, and life span in the adult housefly, Musca domestica. Exp. Gerontol. 22, 59-65.

Fernandez, J. R., Grant, M. D., Tulli, N. M., Karkowski, L. M., and Mcclearn, G. E. (1999). Differences in locomotor activity across the lifespan of Drosophila melanogaster. Exp. Gerontol. 34, 621-631.

Finch, C. E., and Ruvkun, G. (2001). The genetics of aging. Annu. Rev. Genomics Hum. Genet. 2, 435-462.

Finch, C. E., and Tanzi, R. E. (1997). Genetics of aging. Science 278, 407-411.

Fisher, A. L. (2004). Of worms and women: sarcopenia and its role in disability and mortality. J. Am. Geriatr. Soc. 52, 1185-1190.

Flajnik, M. F., and Du Pasquier, L. (2004). Evolution of innate and adaptive immunity: can we draw a line? Trends Immunol. 25, 640-644.

Flatt, T., Heyland, A., Rus, F., Porpiglia, E., Sherlock, C., Yamamoto, R., Garbuzov, A., Palli, S. R., Tatar, M., and Silverman, N. (2008a). Hormonal regulation of the humoral innate immune response in Drosophila melanogaster. J. Exp. Biol. 211, 2712-2724.

Flatt, T., Min, K. J., D’Alterio, C., VillaCuesta, E., Cumbers, J., Lehmann, R., Jones, D. L., and Tatar, M. (2008b). Drosophila germ-line modulation of insulin signaling and lifespan. Proc. Natl. Acad. Sci. U.S.A. 105, 6368-6373.

Flatt, T., and Promislow, D. E. (2007). Physiology. Still pondering an age-old question. Science 318, 1255-1256.

Fois, C., Medioni, J., and Le Bourg, E. (1991). Habituation of the proboscis extension response as a function of age in Drosophila melanogaster. Gerontology 37, 187-192.

Force, A. G., Staples, T., Soliman, S., and Arking, R. (1995). Comparative biochemical and stress analysis of genetically selected Drosophila strains with different longevities. Dev. Genet. 17, 340-351.

Fowler, K., and Partridge, L. (1989). A cost of mating in female fruitflies. Nature 338, 760-761.

Fresquet, N., and Medioni, J. (1993). Effects of ageing on visual discrimination learning in Drosophila melanogaster. Q. J. Exp. Psychol. B. 46, 399-412.

Gavrilov, L. A., and Gavrilova, N. S. (1999). Is there a reproductive cost for human longevity? J. Anti Aging Med. 2, 121-123.

Gavrilova, N. S., and Gavrilov, L. A. (2005). "Human fertility and reproduction an evolutionary perspective," in Grandmotherhood: The Evolutionary Significance of The Second Half Female Life, eds E. Voland, A. Chasiotis, and W. Schiefenhoevel (New Brunswick: Rutgers University Press), 59-80.

Gems, D., Sutton, A. J., Sundermeyer, M. L., Albert, P. S., King, K. V., Edgley, M. L., Larsen, P. L., and Riddle, D. L. (1998). Two pleiotropic classes of daf-2 mutation affect larval arrest, adult behavior, reproduction and longevity in Caenorhabditis elegans. Genetics 150, 129-155.

Gerber, B., and Stocker, R. F. (2007). The Drosophila larva as a model for studying chemosensation and chemosensory learning: a review. Chem. Senses 32, 65-89.

Goddeeris, M. M., Cook-Wiens, E., Horton, W. J., Wolf, H., Stoltzfus, J. R., Borrusch, M., and Grotewiel, M. S. (2003). Delayed behavioural aging and altered mortality in Drosophila beta integrin mutants. Aging Cell 2, 257-264.

Good, T. P., and Tatar, M. (2001). Agespecific mortality and reproduction respond to adult dietary restriction 
in Drosophila melanogaster. J. Insect Physiol. 47, 1467-1473.

Grady, C. L. (2008). Cognitive neuroscience of aging. Ann. N. Y. Acad. Sci. 1124, 127-144.

Griffith, L. C., and Ejima, A. (2009). Courtship learning in Drosophila melanogaster: diverse plasticity of a reproductive behavior. Learn. Mem. $16,743-750$

Grotewiel, M. S., Martin, I., Bhandari, P., and Cook-Wiens, E. (2005). Functional senescence in Drosophila melanogaster. Ageing Res. Rev. 4, 372-397.

Guarente, L., and Kenyon, C. (2000). Genetic pathways that regulate ageing in model organisms. Nature 408, 255-262.

Hari, R., Burde, V., and Arking, R. (1998). Immunological confirmation of elevated levels of CuZn superoxide dismutase protein in an artificially selected long-lived strain of Drosophila melanogaster. Exp. Gerontol. 33, 227-237.

Harman, D. (1956). Aging: a theory based on free radical and radiation chemistry. J. Gerontol. 11, 298-300.

Heisenberg, M., Wolf, R., and Brembs, B. (2001). Flexibility in a single behavioral variable of Drosophila. Learn. Mem. 8, 1-10.

Hekimi, S. (2006). How genetic analysis tests theories of animal aging. Nat. Genet. 38, 985-991.

Helfand, S. L., and Rogina, B. (2003). From genes to aging in Drosophila. Adv. Genet. 49, 67-109.

Hertzog, C., Dixon, R. A., Hultsch, D. F., and Macdonald, S. W. (2003). Latent change models of adult cognition: are changes in processing speed and working memory associated with changes in episodic memory? Psychol. Aging 18, 755-769.

Hirano, Y., Kuriyama, Y., Miyashita, T., Horiuchi, J., and Saitoe, M. (2012). Reactive oxygen species are not involved in the onset of age-related memory impairment in Drosophila. Genes Brain Behav. 11, 79-86.

Hoffmann, J. A. (2003). The immune response of Drosophila. Nature 426, 33-38.

Honda, Y., and Honda, S. (1999). The daf-2 gene network for longevity regulates oxidative stress resistance and $\mathrm{Mn}$-superoxide dismutase gene expression in Caenorhabditis elegans. FASEB J. 13, 1385-1393.

Horiuchi, J., and Saitoe, M. (2005). Can flies shed light on our own agerelated memory impairment? Ageing Res. Rev. 4, 83-101.

Hwangbo, D. S., Gershman, B., Tu, M. P., Palmer, M., and Tatar, M. (2004).
Drosophila dFOXO controls lifespan and regulates insulin signalling in brain and fat body. Nature 429, 562-566.

Iliadi, K. G., and Boulianne, G. L. (2010). Age-related behavioral changes in Drosophila. Ann. N. Y. Acad. Sci. 1197, 9-18.

Jafari, M., Long, A. D., Mueller, L. D., and Rose, M. R. (2006). The pharmacology of ageing in Drosophila. Curr. Drug Targets 7, 1479-1483.

Johnson, T. E. (2008). Caenorhabditis elegans 2007: the premier model for the study of aging. Exp. Gerontol. 43, $1-4$.

Johnson, T. E., Tedesco, P. M., and Lithgow, G. J. (1993). Comparing mutants, selective breeding, and transgenics in the dissection of aging processes of Caenorhabditis elegans. Genetica 91, 65-77.

Kamyshev, N. G., Iliadi, K. G., and Bragina, J. V. (1999). Drosophila conditioned courtship: two ways of testing memory. Learn. Mem. 6, 1-20.

Kenyon, C., Chang, J., Gensch, E., Rudner, A., and Tabtiang, R. (1993). A C. elegans mutant that lives twice as long as wild type. Nature 366, 461-464.

Kernan, M. J. (2007). Mechanotransduction and auditory transduction in Drosophila. Pflugers Arch. 454, 703-720.

Kim, J. H., Kwak, H. B., Leeuwenburgh, C., and Lawler, J. M. (2008). Lifelong exercise and mild (8\%) caloric restriction attenuate age-induced alterations in plantaris muscle morphology, oxidative stress and IGF-1 in the Fischer-344 rat. Exp. Gerontol. $43,317-329$.

Kim, S., Benguria, A., Lai, C. Y., and Jazwinski, S. M. (1999). Modulation of life-span by histone deacetylase genes in Saccharomyces cerevisiae. Mol. Biol. Cell 10, 3125-3136.

Kirkwood, T. B. (1977). Evolution of ageing. Nature 270, 301-304.

Koubova, J., and Guarente, L. (2003). How does calorie restriction work? Genes Dev. 17, 313-321.

Kurtz, J. (2002). Phagocytosis by invertebrate hemocytes: causes of individual variation in Panorpa vulgaris scorpionflies. Microsc. Res. Tech. 57, 456-468.

Landis, G. N., Abdueva, D., Skvortsov, D., Yang, J., Rabin, B. E., Carrick, J., Tavare, S., and Tower, J. (2004). Similar gene expression patterns characterize aging and oxidative stress in Drosophila melanogaster. Proc. Natl. Acad. Sci. U.S.A. 101, 7663-7668.

Larsson, L., Sjodin, B., and Karlsson, J. (1978). Histochemical and biochemical changes in human skeletal muscle with age in sedentary males, age 22-65 years. Acta Physiol. Scand. 103, 31-39.

Le Bourg, E. (1983). Aging and habituation of the tarsal response in Drosophila melanogaster. Gerontology 29, 388-393.

Le Bourg, E. (2001a). A mini-review of the evolutionary theories of aging, is it the time to accept them? Demogr. Res. 4, 1-28.

Le Bourg, E. (2001b). Oxidative stress, aging and longevity in Drosophila melanogaster. FEBS Lett. 498, 183-186.

Le Bourg, E. (2007). Does reproduction decrease longevity in human beings? Ageing Res. Rev. 6, 141-149.

Le Bourg, E., and Lints, F. A. (1984). A longitudinal study of the effects of age on spontaneous locomotor activity in Drosophila melanogaster. Gerontology 30, 79-86.

Le Bourg, E., Thon, B., Legare, J., Desjardins, B., and Charbonneau, $\mathrm{H}$. (1993). Reproductive life of FrenchCanadians in the 17-18th centuries: a search for a trade-off between early fecundity and longevity. Exp. Gerontol. 28, 217-232.

Levinoff, E. J., Li, K. Z., Murtha, S., and Chertkow, H. (2004). Selective attention impairments in Alzheimer's disease: evidence for dissociable components. Neuropsychology 18 580-588.

Lin, Y. J., Seroude, L., and Benzer, S. (1998). Extended life-span and stress resistance in the Drosophila mutant methuselah. Science 282, 943-946.

Lopez, L. M., Harris, S. E., Luciano, M., Liewald, D., Davies, G., Gow, A. J., Tenesa, A., Payton, A., Ke, X. Whalley, L. J., Fox, H., Haggerty, P., Ollier, W., Pickles, A., Porteous, D. J., Horan, M. A., Pendleton, N., Starr, J. M., and Deary, I. J. (2012). Evolutionary conserved longevity genes and human cognitive abilities in elderly cohorts. Eur. J. Hum. Genet. 20, 341-347.

Lu, B. (2009). Recent advances in using Drosophila to model neurodegenerative diseases. Apoptosis 14, 1008-1020.

Luckinbill, L. S., Grudzien, T. A., Rhine, S., and Weisman, G. (1989). The genetic basis of adaptation to selection for longevity in Drosophila melanogaster. Evol. Ecol. 3, 31-39.

Luo, S., and Murphy, C. T. (2011). Caenorhabditis elegans reproductive aging: regulation and underlying mechanisms. Genesis 49, 53-65.

Lycett, J. E., Dunbar, R. I., and Voland, E. (2000). Longevity and the costs of reproduction in a historical human population. Proc. Biol. Sci. 267, 31-35.

Mackay, W. J., and Bewley, G. C. (1989). The genetics of catalase in Drosophila melanogaster: isolation and characterization of acatalasemic mutants. Genetics 122, 643-652.

Mackenzie, D. K., Bussiere, L. F., and Tinsley, M. C. (2011). Senescence of the cellular immune response in Drosophila melanogaster. Exp. Gerontol. 46, 853-859.

Mair, W., and Dillin, A. (2008). Aging and survival: the genetics of life span extension by dietary restriction. Annu. Rev. Biochem. 77, 727-754.

Marden, J. H., Rogina, B., Montooth, K. L., and Helfand, S. L. (2003). Conditional tradeoffs between aging and organismal performance of Indy long-lived mutant flies. Proc. Natl. Acad. Sci. U.S.A. 100, 3369-3373.

Martin, I., Jones, M. A., Rhodenizer, D., Zheng, J., Warrick, J. M., Seroude, L., and Grotewiel, M. (2009). Sod2 knockdown in the musculature has whole-organism consequences in Drosophila. Free Radic. Biol. Med. 47, 803-813.

Martinez, V. G., Javadi, C. S., Ngo, E., Ngo, L., Lagow, R. D., and Zhang, B. (2007). Age-related changes in climbing behavior and neural circuit physiology in Drosophila. Dev. Neurobiol. 67, 778-791.

Marzetti, E., Lees, H. A., Wohlgemuth, S. E., and Leeuwenburgh, C. (2009). Sarcopenia of aging: underlying cellular mechanisms and protection by calorie restriction. Biofactors 35 , 28-35.

McArdle, P. F., Pollin, T. I., O'Connell, J. R., Sorkin, J. D., Agarwala, R., Schaffer, A. A., Streeten, E. A., King, T. M., Shuldiner, A. R., and Mitchell, B. D. (2006). Does having children extend life span? A genealogical study of parity and longevity in the Amish. J. Gerontol. A Biol. Sci. Med. Sci. 61, 190-195.

McDowd, J. M., and Shaw, R. J. (2000). "Aging and attention: a functional prespective," in Handbook of Aging and Cognition, 2nd Edn. eds F. I. M. Craik and T. A. Salthouse (Mahwah: Lawrence Erlbaum Associates), 221-292.

Mery, F. (2007). Aging and its differential effects on consolidated memory forms in Drosophila. Exp. Gerontol. 42, 99-101.

Migliaccio, E., Giorgio, M., Mele, S., Pelicci, G., Reboldi, P., Pandolfi, P. P., Lanfrancone, L., and Pelicci, P. G. (1999). The p66shc adaptor protein controls oxidative stress response and life span in mammals. Nature 402, 309-313. 
Miller, M. S., Lekkas, P., Braddock, J. M., Farman, G. P., Ballif, B. A., Irving, T. C., Maughan, D. W., and Vigoreaux, J. O. (2008). Aging enhances indirect flight muscle fiber performance yet decreases flight ability in Drosophila. Biophys. J. 95, 2391-2401.

Miquel, J., Lundgren, P. R., Bensch, K. G., and Atlan, H. (1976). Effects of temperature on the life span, vitality and fine structure of Drosophila melanogaster. Mech. Ageing Dev. 5, 347-370.

Mitteldorf, J. (2010). Female fertility and longevity. Age (Dordr.) 32, 79-84.

Mockett, R. J., Orr, W. C., Rahmandar, J. J., Sohal, B. H., and Sohal, R. S. (2001). Antioxidant status and stress resistance in long- and short-lived lines of Drosophila melanogaster. Exp. Gerontol. 36, 441-463.

Muller, H. G., Chiou, J. M., Carey, J. R., and Wang, J. L. (2002). Fertility and life span: late children enhance female longevity. $J$. Gerontol. A Biol. Sci. Med. Sci. 57, B202-B206.

Murakami, S. (2006). Stress resistance in long-lived mouse models. Exp. Gerontol. 41, 1014-1019.

Murray, M. J., and Meacham, R. B. (1993). The effect of age on male reproductive function. World J. Urol. 11, 137-140.

Nair, K. S. (2005). Aging muscle. Am. J. Clin. Nutr. 81, 953-963.

Nishimura, M., Ocorr, K., Bodmer, R., and Cartry, J. (2011). Drosophila as a model to study cardiac aging. Exp. Gerontol. 46, 326-330.

Novoseltsev, V. N., Arking, R., Carey, J. R., Novoseltseva, J. A., and Yashin, A. I. (2005). Individual fecundity and senescence in Drosophila and medfly. J. Gerontol. A Biol. Sci. Med. Sci. 60, 953-962.

Nybo, H., Petersen, H. C., Gaist, D., Jeune, B., Andersen, K., Mcgue, M., Vaupel, J. W., and Christensen, K. (2003). Predictors of mortality in 2,249 nonagenarians-the Danish 1905-Cohort Survey. J. Am. Geriatr. Soc. 51, 1365-1373.

Oberauer, K., Wendland, M., and Kliegl, R. (2003). Age differences in working memory - the roles of storage and selective access. Mem. Cognit. 31, 563-569.

Orr, W. C., Mockett, R. J., Benes, J. J., and Sohal, R. S. (2003). Effects of overexpression of copper-zinc and manganese superoxide dismutases, catalase, and thioredoxin reductase genes on longevity in Drosophila melanogaster. J. Biol. Chem. 278, 26418-26422.
Orr, W. C., and Sohal, R. S. (1992). The effects of catalase gene overexpression on life span and resistance to oxidative stress in transgenic Drosophila melanogaster. Arch. Biochem. Biophys. 297, 35-41.

Orr, W. C., and Sohal, R. S. (1993). Effects of $\mathrm{Cu}-\mathrm{Zn}$ superoxide dismutase overexpression on life span and resistance to oxidative stress in transgenic Drosophila melanogaster. Arch. Biochem. Biophys. 301, 34-40.

Orr, W. C., and Sohal, R. S. (1994). Extension of life-span by overexpression of superoxide dismutase and catalase in Drosophila melanogaster. Science 263, 1128-1130.

Orr, W. C., and Sohal, R. S. (2003). Does overexpression of $\mathrm{Cu}, \mathrm{Zn}$ SOD extend life span in Drosophila melanogaster? Exp. Gerontol. 38, 227-230.

Pan, L., Chen, S., Weng, C., Call, G., Zhu, D., Tang, H., Zhang, N., and Xie, T. (2007). Stem cell aging is controlled both intrinsically and extrinsically in the Drosophila ovary. Cell Stem Cell 1, 458-469.

Park, J. W., Ji, Y. I., Choi, Y. H., Kang, M. Y., Jung, E., Cho, S. Y., Cho, H. Y., Kang, B. K., Joung, Y. S., Kim, D. H., Park, S. C., and Park, J. (2009). Candidate gene polymorphisms for diabetes mellitus, cardiovascular disease and cancer are associated with longevity in Koreans. Exp. Mol. Med. 41, 772-781.

Parkes, T. L., Elia, A. J., Dickinson, D., Hilliker, A. J., Phillips, J. P., and Boulianne, G. L. (1998). Extension of Drosophila lifespan by overexpression of human SOD1 in motorneurons. Nat. Genet. 19, 171-174.

Partridge, L., and Farquhar, M. (1981). Sexual activity reduces lifespan of male fruitflies. Nature 294, 580-582.

Partridge, L., Gems, D., and Withers, D. J. (2005). Sex and death: what is the connection? Cell 120, 461-472.

Partridge, L., Green, A., and Fowler, K. (1987). Effects of egg-production and of exposure to males on female survival in Drosophila melanogaster. J. Insect Physiol. 33, 745-749.

Partridge, L., Prowse, N., and Pignatelli, P. (1999). Another set of responses and correlated responses to selection on age at reproduction in Drosophila melanogaster. Proc. Biol. Sci. 266, 255-261.

Pearl, R. (1928). The Rate of Living. London: University of London Press.

Perry, R. J., Watson, P., and Hodges, J. R. (2000). The nature and staging of attention dysfunction in early (minimal and mild) Alzheimer's disease: relationship to episodic and semantic memory impairment. Neuropsychologia 38, 252-271.

Phillips, J. P., Campbell, S. D., Michaud, D., Charbonneau, M., and Hilliker, A. J. (1989). Null mutation of copper/zinc superoxide dismutase in Drosophila confers hypersensitivity to paraquat and reduced longevity. Proc. Natl. Acad. Sci. U.S.A. 86, 2761-2765.

Piazza, N., Hayes, M., Martin, I., Duttaroy, A., Grotewiel, M., and Wessells, R. (2009). Multiple measures of functionality exhibit progressive decline in a parallel, stochastic fashion in Drosophila Sod2 null mutants. Biogerontology 10, 637-648.

Pick, S., and Strauss, R. (2005). Goaldriven behavioral adaptations in gap-climbing Drosophila. Curr. Biol. 15, 1473-1478.

Pletcher, S. D., Macdonald, S. J., Marguerie, R., Certa, U., Stearns, S C., Goldstein, D. B., and Partridge, L. (2002). Genome-wide transcript profiles in aging and calorically restricted Drosophila melanogaster. Curr. Biol. 12, 712-723.

Prelog, M. (2006). Aging of the immune system: a risk factor for autoimmunity? Autoimmun. Rev. 5, 136-139.

Puca, A. A., Daly, M. J., Brewster, S. J., Matise, T. C., Barrett, J., SheaDrinkwater, M., Kang, S., Joyce, E., Nicoli, J., Benson, E., Kunkel, L. M., and Perls, T. (2001). A genome-wide scan for linkage to human exceptional longevity identifies a locus on chromosome 4. Proc. Natl. Acad. Sci. U.S.A. 98, 10505-10508.

Quinn, W. G., Harris, W. A., and Benzer, S. (1974). Conditioned behavior in Drosophila melanogaster. Proc. Natl. Acad. Sci. U.S.A. 71, 708-712.

Ramsden, S., Cheung, Y. Y., and Seroude, L. (2008). Functional analysis of the Drosophila immune response during aging. Aging Cell 7, 225-236.

Reiter, L. T., Potocki, L., Chien, S. Gribskov, M., and Bier, E. (2001). A systematic analysis of human disease-associated gene sequences in Drosophila melanogaster. Genome Res. 11, 1114-1125.

Reveillaud, I., Niedzwiecki, A., Bensch, K. G., and Fleming, J. E. (1991). Expression of bovine superoxide dismutase in Drosophila melanogaster augments resistance of oxidative stress. Mol. Cell. Biol. 11, 632-640.

Rhodenizer, D., Martin, I., Bhandari, P., Pletcher, S. D., and Grotewiel, M. (2008). Genetic and environmental factors impact agerelated impairment of negative geotaxis in Drosophila by altering age-dependent climbing speed. Exp. Gerontol. 43, 739-748.
Riha, V. F., and Luckinbill, L. S. (1996). Selection for longevity favors stringent metabolic control in Drosophila melanogaster. J. Gerontol. A Biol. Sci. Med. Sci. 51, B284-B294.

Robberecht, W. (2000). Oxidative stress in amyotrophic lateral sclerosis. $J$. Neurol. 247(Suppl. 1), I1-I6.

Rogina, B., Helfand, S. L., and Frankel, S. (2002). Longevity regulation by Drosophila Rpd3 deacetylase and caloric restriction. Science 298, 1745.

Rogina, B., Wolverton, T., Bross, T. G. Chen, K., Muller, H. G., and Carey, J. R. (2007). Distinct biological epochs in the reproductive life of female Drosophila melanogaster. Mech. Ageing Dev. 128, 477-485.

Rose, M. R. (1991). Evolutionary Biology of Aging. New York: Oxford University Press.

Rose, M. R. (1999). Genetics of aging in Drosophila. Exp. Gerontol. 34, 577-585.

Rose, M. R., and Bradley, T. J. (1998). Evolutionary physiology of the cost of reproduction. Oikos 83, 443-451.

Ruan, H., Tang, X. D., Chen, M. L., Joiner, M. L., Sun, G., Brot, N., Weissbach, H., Heinemann, S. H., Iverson, L., Wu, C. F., and Hoshi, T. (2002). High-quality life extension by the enzyme peptide methionine sulfoxide reductase. Proc. Natl. Acad. Sci. U.S.A. 99, 2748-2753.

Saitoe, M., Horiuchi, J., Tamura, T., and Ito, N. (2005). Drosophila as a novel animal model for studying the genetics of age-related memory impairment. Rev. Neurosci. 16, 137-149.

Salmon, A. B., Richardson, A., and Perez, V. I. (2010). Update on the oxidative stress theory of aging: does oxidative stress play a role in aging or healthy aging? Free Radic. Biol. Med. 48, 642-655.

Sarup, P., Sorensen, P., and Loeschcke, V. (2011). Flies selected for longevity retain a young gene expression profile. Age (Dordr.) 33, 69-80.

Savvateeva, E. V., Popov, A. V., Kamyshev, N. G., Iliadi, K. G., Bragina, J. V., Heisenberg, M., Kornhuber, J., and Riederer, P. (1999). Age-dependent changes in memory and mushroom bodies in the Drosophila mutant vermilion deficient in the kynurenine pathway of tryptophan metabolism. Ross. Fiziol. Zh. Im. IM. Sechenova. 85, 167-183.

Seroude, L., Brummel, T., Kapahi, P., and Benzer, S. (2002). Spatio-temporal analysis of gene expression during aging in Drosophila melanogaster. Aging Cell 1, 47-56.

Service, P. M. (1993). Laboratory evolution of longevity and reproductive 
fitness components in male fruit flies: mating ability. Evolution 47, 387-399.

Service, P. M., Hutchinson, E. W., Mackinley, M. D., and Rose, M. R. (1985). Resistance to environmental stress in Drosophila melanogaster selected for postponed senescence. Physiol. Zool. 58, 380-389.

Seto, N. O., Hayashi, S., and Tener, G. M. (1990). Overexpression of Cu-Zn superoxide dismutase in Drosophila does not affect life-span. Proc. Natl. Acad. Sci. U.S.A. 87, 4270-4274.

Sgro, C. M., and Partridge, L. (1999). A delayed wave of death from reproduction in Drosophila. Science 286, 2521-2524.

Siegel, R. W., and Hall, J. C. (1979). Conditioned responses in courtship behavior of normal and mutant Drosophila. Proc. Natl. Acad. Sci. U.S.A. 76, 3430-3434.

Simon, A. F., Liang, D. T., and Krantz, D. E. (2006). Differential decline in behavioral performance of Drosophila melanogaster with age. Mech. Ageing Dev. 127, 647-651.

Simon, A. F., Shih, C., Mack, A., and Benzer, S. (2003). Steroid control of longevity in Drosophila melanogaster. Science 299, 1407-1410.

Skinner, C., and Lin, S. J. (2010). Effects of calorie restriction on life span of microorganisms. Appl. Microbiol. Biotechnol. 88, 817-828.

Smith, M. A., Rottkamp, C. A., Nunomura, A., Raina, A. K., and Perry, G. (2000). Oxidative stress in Alzheimer's disease. Biochim. Biophys. Acta 1502, 139-144.

Soerensen, M., Dato, S., Christensen, K., Mcgue, M., Stevnsner, T., Bohr, V. A., and Christiansen, L. (2010). Replication of an association of variation in the FOXO3A gene with human longevity using both case-control and longitudinal data. Aging Cell 9, 1010-1017.

Sohal, R. S. (1986). "The rate of living theory: a contemporary interpretation," in Comparative Biology of Aging in Insects, eds K. G. Collatz and R. S. Sohal (Heiddelberg: Springer-Verlag), 23-44.

Sohal, R. S., and Weindruch, R. (1996). Oxidative stress, caloric restriction, and aging. Science 273, 59-63.

Speakman, J. R., Talbot, D. A., Selman, C., Snart, S., Mclaren, J. S., Redman, P., Krol, E., Jackson, D. M., Johnson, M. S., and Brand, M. D.
(2004). Uncoupled and surviving: individual mice with high metabolism have greater mitochondrial uncoupling and live longer. Aging Cell 3, 87-95.

Spirduso, W. W., Francis, K. L. and Macrae, P. G. (2005). Physical Dimensions of Aging, 2nd edn. Champaign, IL: Human Kinetics, $\mathrm{x}+374$.

Stocker, R. F. (2004). Taste perception: Drosophila - a model of good taste. Curr. Biol. 14, R560-R561.

Sun, J., and Tower, J. (1999). FLP recombinase-mediated induction of $\mathrm{Cu} / \mathrm{Zn}$-superoxide dismutase transgene expression can extend the life span of adult Drosophila melanogaster flies. Mol. Cell. Biol. 19, 216-228.

Tamura, T., Chiang, A. S., Ito, N., Liu, H. P., Horiuchi, J., Tully, T., and Saitoe, M. (2003). Aging specifically impairs amnesiac-dependent memory in Drosophila. Neuron 40 , 1003-1011.

Tang, H. (2009). Regulation and function of the melanization reaction in Drosophila. Fly (Austin) 3, 105-111.

Tan, Q., Zhao, J. H., Iachine, I., Hjelmborg, J., Vach, W., Vaupel, J. W., Christensen, K., and Kruse, T. A. (2004). Power of non-parametric linkage analysis in mapping genes contributing to human longevity in long-lived sib-pairs. Genet. Epidemiol. 26, 245-253.

Tatar, M. (2010). Reproductive aging in invertebrate genetic models. Ann. N. Y. Acad. Sci. 1204, 149-155.

Tatar, M., Kopelman, A., Epstein, D., Tu, M. P., Yin, C. M., and Garofalo, R. S. (2001). A mutant Drosophila insulin receptor homolog that extends life-span and impairs neuroendocrine function. Science 292, 107-110.

Tatone, C., Amicarelli, F., Carbone, M. C., Monteleone, P., Caserta, D., Marci, R., Artini, P. G., Piomboni, P., and Focarelli, R. (2008). Cellular and molecular aspects of ovarian follicle ageing. Hum. Reprod. Update 14, 131-142.

Taub, J., Lau, J. F., Ma, C., Hahn, J. H., Hoque, R., Rothblatt, J., and Chalfie, M. (1999). A cytosolic catalase is needed to extend adult lifespan in C. elegans daf-C and clk-1 mutants. Nature 399, 162-166.

te Velde, E. R., and Pearson, P. L. (2002). The variability of female reproductive ageing. Hum. Reprod. Update 8, 141-154.

Tempel, B. L., Bonini, N., Dawson, D. R., and Quinn, W. G. (1983). Reward learning in normal and mutant Drosophila. Proc. Natl. Acad. Sci. U.S.A. 80, 1482-1486.

Thomas, F., Teriokhin, A. T., Renaud, F., De Meeuãs, T., and Gueâgan, J. F. (2000). Human longevity at the cost of reproductive success: evidence from global data. J. Evol. Biol. 13, 409-414.

Ting, C. Y., and Lee, C. H. (2007). Visual circuit development in Drosophila. Curr. Opin. Neurobiol. 17, 65-72.

Tissenbaum, H. A., and Guarente, L. (2001). Increased dosage of a sir-2 gene extends lifespan in Caenorhabditis elegans. Nature 410 227-230.

Tower, J. (2000). Transgenic methods for increasing Drosophila life span. Mech. Ageing Dev. 118, 1-14.

Tully, T., and Quinn, W. G. (1985). Classical conditioning and retention in normal and mutant Drosophila melanogaster. J. Comp. Physiol. A 157, 263-277.

Tyler, R. H., Brar, H., Singh, M., Latorre, A., Graves, J. L., Mueller, L. D., Rose, M. R., and Ayala, F. J. (1993). The effect of superoxide dismutase alleles on aging in Drosophila. Genetica 91, 143-149.

van Swinderen, B. (2007). Attentionlike processes in Drosophila require short-term memory genes. Science 315, 1590-1593.

Van Voorhies, W. A. (2004). Live fast live long? A commentary on a recent paper by Speakman et al. Aging Cell 3, 327-330.

Verhaeghen, P., and Cerella, J. (2002). Aging, executive control, and attention: a review of meta-analyses. $\mathrm{Neu}$ rosci. Biobehav. Rev. 26, 849-857.

Vrailas-Mortimer, A., Del Rivero, T., Mukherjee, S., Nag, S., Gaitanidis, A., Kadas, D., Consoulas, C., Duttaroy, A., and Sanyal, S. (2011). A musclespecific p38 MAPK/Mef2/MnSOD pathway regulates stress, motor function, and life span in Drosophila. Dev. Cell 21, 783-795.

Westendorp, R. G., and Kirkwood, T. B. (1998). Human longevity at the cost of reproductive success. Nature 396 743-746.

Whitehorn, P. R., Tinsley, M. C., Brown, M. J., Darvill, B., and Goulson, D. (2011). Genetic diversity, parasite prevalence and immunity in wild bumblebees. Proc. Biol. Sci. 278, 1195-1202.

Williams, G. C. (1957). Pleiotropy, natural selection, and the evolution of senescence. Evolution 11, 398-411.

Williams, M. J. (2007). Drosophila hemopoiesis and cellular immunity. J. Immunol. 178, 4711-4716.

Wustmann, G., and Heisenberg, M. (1997). Behavioral manipulation of retrieval in a spatial memory task for Drosophila melanogaster. Learn. Mem. 4, 328-336.

Yamazaki, D., Horiuchi, J., Nakagami, Y., Nagano, S., Tamura, T., and Saitoe, M. (2007). The Drosophila DCO mutation suppresses agerelated memory impairment without affecting lifespan. Nat. Neurosci. 10, 478-484.

Zerofsky, M., Harel, E., Silverman, N., and Tatar, M. (2005). Aging of the innate immune response in Drosophila melanogaster. Aging Cell 4, 103-108.

Zhang, K., Guo, J. Z., Peng, Y., Xi, W., and Guo, A. (2007). Dopamine-mushroom body circuit regulates saliency-based decisionmaking in Drosophila. Science 316, 1901-1904.

Zwaan, B., Bijlsma, R., and Hoekstra, R. F. (1995). Direct selection on life span in Drosophila melanogaster. Evolution 49, 649-659.

Conflict of Interest Statement: The authors declare that the research was conducted in the absence of any commercial or financial relationships that could be construed as a potential conflict of interest.

Received: 05 March 2012; paper pending published: 01 April 2012; accepted: 03 April 2012; published online: 18 April 2012.

Citation: Iliadi KG, Knight $D$ and Boulianne GL (2012) Healthy aging insights from Drosophila. Front. Physio. 3:106. doi: 10.3389/fphys.2012.00106 This article was submitted to Frontiers in Integrative Physiology, a specialty of Frontiers in Physiology.

Copyright (c) 2012 Iliadi, Knight and Boulianne. This is an open-access article distributed under the terms of the Creative Commons Attribution Non Commercial License, which permits noncommercial use, distribution, and reproduction in other forums, provided the original authors and source are credited. 